Research paper

\title{
Extended and local structural description of a kaolinitic clay, its fired ceramics and intermediates: An XRD and XANES analysis
}

\author{
L. Andrini ${ }^{\text {a }}$, M.R. Gauna ${ }^{\text {b }}$, M.S. Conconi ${ }^{\text {b }}$, G. Suarez ${ }^{\text {b,c }}$, F.G. Requejo ${ }^{\text {a,d }}$, E.F. Aglietti ${ }^{\text {b,c }}$, N.M. Rendtorff ${ }^{\text {b,c, }}$ \\ a Instituto de Fisicoquímica Teórica y Aplicada (INIFTA) (UNLP-CONICET CCT La Plata), 64 y Diagonal, 113 La Plata, Argentina \\ b Centro de Tecnología de Recursos Minerales y Cerámica (CETMIC): (CIC-CONICET CCT La Plata), Camino Centenario y 506, C.C.49, B1897ZCA M.B. Gonnet, Argentina \\ c Dpto. De Química, Facultad de Ciencias Exactas, Universidad Nacional de La Plata, UNLP, La Plata, Argentina \\ d Dpto. de Física, Facultad de Ciencias Exactas, Universidad Nacional de La Plata, La Plata, Argentina
}

\section{A R T I C L E I N F O}

\section{Article history:}

Received 28 July 2015

Received in revised form 28 January 2016

Accepted 30 January 2016

Available online 8 February 2016

\section{Keywords:}

Kaolinitic clay

Firing transformations

X-ray absorption

Al K-XANES

\begin{abstract}
A B S T R A C T
The thermal transformations processes of kaolinite $(\mathrm{K})$ in kaolinitic clays is known to consist of a dehydroxylation into metakaolin (MK) at $\approx 600^{\circ} \mathrm{C}$, followed by the formation of a spinel type aluminosilicate (SAS) at $\approx 980^{\circ} \mathrm{C}$, and finally the development of mullite $(\mathrm{M})$ at higher temperatures $\left(1200-1300{ }^{\circ} \mathrm{C}\right)$.

The structural characterization of these materials is generally based on X-ray diffraction (XRD) studies, where the XRD features of $\mathrm{K}$ and $\mathrm{M}$ are well defined due to their crystalline nature, but as consequence of the low crystallinity of MK and SAS, the precise characterization of these phases is not possible using this technique.

In this study the nature of aluminum atoms in the different materials obtained by thermal treatments of a kaolinite is investigated using Al K-XANES and compared with other well-known aluminum containing materials. XRD and SEM characterization were also carried out.

The results confirm the potentiality of this synchrotron based techniques for the characterization of natural materials and ceramics especially with low crystallinity. Particularly the mullite aluminums Al K-XANES spectra were not reported before.
\end{abstract}

(c) 2016 Elsevier B.V. All rights reserved.

\section{Introduction}

Kaolinite $\left(\mathrm{K}: \mathrm{Al}_{2} \mathrm{O}_{3} \cdot 2 \mathrm{SiO}_{2} \cdot 4 \mathrm{H}_{2} \mathrm{O}\right)$ is classified as a $1: 1$ dioctahedral phyllosilicate and it is the main component of the kaolin group of minerals. The importance of kaolinitic clays in the development of modern ceramic science can best be appreciated by considering its widespread influence on ceramic, material science, and mineralogy (Chakraborty, 2014). These clays have been widely used in different technological applications for thousands of years. The majority of the applications include a thermal treatment. The firing transformations of this family of raw materials have been widely studied (Carty and Senapati, 1998; Iqbal and Lee, 2000; Lee et al., 2008; Carbajal et al., 2007; Lisiane et al., 2012).

In kaolinitic clays the principal clay crystalline phase is kaolinite, and it is usually present with other phases like quartz, feldspars and titania. (Serra et al., 2013). The kaolinite thermal transformations are affected by heating treatments (rate, dwell and atmosphere) and presence of impurities or additives and particle size (Chakraborty, 2014).

Kaolinitic clays are utilized in a large variety of industrial applications such as ceramics, refractories, cement, filling agent in paper, plastics, rubber, cosmetics, etc. In order to reach the desired properties,

\footnotetext{
* Corresponding author.

E-mail address: rendtorff@cetmic.unlp.edu.ar (N.M. Rendtorff).
}

thermal treatments are involved in the majority of these applications (Liu et al., 2003; She and Ohji, 2003; Lee et al., 2008).

The classic papers of Brindley and Nakahira reported for the first time a systematic study of phase transformations for the kaolinitemullite series (Blinder and Nakahira, 1959a, b), and measured the transformation temperature for a model material. The actual temperature transformations can be evaluated by several thermal analysis techniques, thermogravimetry, differential thermal analysis, calorimetry, etc. (Chakraborty, 2014).

In fact, the particular properties, like chemical composition, particle size, transformation temperature, etc., of each raw natural material depend on the different geochemical constitutions of these materials including impurities, in consequence, heating rates, for example, are affected by geochemistry of each material (Chakraborty, 2014).

The kaolinite-mullite series was recently studied by means of powder neutron diffraction (De Aza et al., 2014) and the MK formation was studied by NMR (Wang et al., 2014). The mechanisms were proposed and corroborated by the employed combined structural and thermal techniques.

Kaolinite (K) dehydroxilation occurs, through a three dimensional diffusion process, with the formation of an amorphous product identified as metakaolinite $\left(\mathrm{MK}: \mathrm{Al}_{2} \mathrm{Si}_{2} \mathrm{O}_{5}\right.$ ); this process is completed above $\sim 650{ }^{\circ} \mathrm{C}$. The metakaolinite remains short-range order at least to $\sim 980{ }^{\circ} \mathrm{C}$. The formation of nanometer size and randomly oriented 
needle-like mullite $\left(\sim 980-992{ }^{\circ} \mathrm{C}\right)$, primary mullite (Mi), side by side with a cubic phase, $\mathrm{Si}-\mathrm{Al}$ spinel (SAS), and amorphous silica-rich at around $\sim 983{ }^{\circ} \mathrm{C}(\mathrm{G})$ was confirmed. The Mi formation is incipient. From $\sim 1136{ }^{\circ} \mathrm{C}$ growth of mullite (Mi) crystals occurs and at $\mathrm{T}>\sim 1200{ }^{\circ} \mathrm{C}$ crystallization of high temperature cristobalite $\left(\mathrm{SiO}_{2}\right)$ from a Si-rich amorphous phase takes place. Between $983{ }^{\circ} \mathrm{C}$ and $1136{ }^{\circ} \mathrm{C}$ is correct to assume that the amount of SAS will be higher than Mi. Additionally, in the Si-rich amorphous phase formed at kaolinite-muscovite interfaces occurs secondary mullite (Mii) crystallization $\left(\sim 1300{ }^{\circ} \mathrm{C}\right)$. The impurities in the starting kaolin can induce a liquid phase during firing (De Aza et al., 2014). Bellotto et al. performed in situ experiments using synchrotron radiation diffraction on kaolin specimens (Bellotto et al., 1995a, b). They study the kinetics of mullite formation in the $1300-1400{ }^{\circ} \mathrm{C}$ temperature range and the kinetics of dehydroxylation of two kaolin specimens in the $500-700{ }^{\circ} \mathrm{C}$ temperature range.

The stoichiometry of the metakaolin corresponds with the kaolinite one, secondly the SAS stoichiometry remains undefined, and finally mullite varies in a small range (Schneider et al., 2008). The vitreous phase $(G)$ belongs to the alumina-silica system, with high silica concentration, accompanied by the different impurities, principally alkali ( $\mathrm{K}$ and $\mathrm{Na}$ ), earthen alkali ( $\mathrm{Ca}$ and $\mathrm{Mg}$ ), iron oxide or titania.

Within the temperature range $\left(\leq 1350^{\circ} \mathrm{C}\right)$ in which the kaolinitic materials are of technological interest, several transformations occur to kaolinite, which we intend to characterize in present study. This can be represented by the following scheme.

$$
\begin{aligned}
& \mathrm{K} \rightarrow \mathrm{MK} \\
& \text { (400-700ÅC) } \\
& \mathrm{MK} \rightarrow \mathrm{SAS}(+\mathrm{G}) \\
& (\approx 980 \AA ⿻) \\
& \mathrm{MK} \rightarrow \mathrm{Mi}(+\mathrm{G}) \\
& (\approx 980 \AA \AA \mathrm{C}) \\
& \mathrm{SAS} \rightarrow \mathrm{Mi}+\mathrm{G} \\
& \text { (1130-1300ÅC) }
\end{aligned}
$$

It is important to point out that the local crystalline nature of MK and SAS is different; MK presents a short range ordering, but no long-range order and therefore no XRD Bragg peaks are present. On the other hand SAS presents some short range order but the crystalline domains (crystallites) are nanosized and therefore are difficult to evaluate this phase using XRD analysis (Serra et al., 2013; Conconi et al., 2014).

In recent years, White et al. used the X-ray Absorption Near Edge Structure (XANES) to study the local environment in metakaolin, which became in a subject of significant debate, particularly with regard to the aluminum coordination environment determination (White et al., 2011). XANES is a powerful and versatile technique for obtaining information about the local atomic environment in materials and can be used to investigate specific elements in solids, liquids, gases or plasma (Koningsberger and Prins, 1998; Bunker, 2010).

The principal objective of the present work consists of the characterization of a series of complex aluminosilicates of technological interest, in the kaolinite-mullite series, by means of X-ray based techniques (XRD and Al K-XANES). This kaolinite-mullite series is obtained by controlled calcination of industrial kaolinitic clay (C-80 caolin PG, Argentina) accompanied by a microstructural observation by means of scanning electron microscopy.

Taking into account the low crystalline nature of some intermediates and products of the mentioned reactions, particularly MK, SAS and G; synchrotron based Al K-XANES arise to be adequate technique for characterizing these particular phases from the local point of view complementing the XRD-Rietveld analyses that evaluates the long distance order of those phases. A pure acid washed kaolinite and a sintered crystalline mullite (pure) are also evaluated for comparison.

\section{Experimental procedure}

\subsection{Studied kaolinitic clay and structural standards}

Industrial kaolinitic clay (C-80 caolin PG, Argentina) was used as model material and two high purity commercially available materials (kaolinite and mullite) were employed as standards for both structural characterizations XRD and Al K-XANES. The chemical composition is shown in Table 1 . The powder presented a mean particle size $\left(D_{50}\right)$ of $4.0 \mu \mathrm{m}$. The mineralogical composition consists of kaolinite (>70\%), quartz and feldspar.

An almost pure, acid washed, kaolinite (98\% kaolinite) (Fischer, Georgia, USA). A commercial Mullite powder was used as the second standard. With Mullite $95 \mathrm{wt} . \%$, glassy phase 5\%, apparent density of $2.80 \mathrm{~g} / \mathrm{cm}^{3}$, true density of $3.13 \mathrm{~g} / \mathrm{cm}^{3}, \mathrm{Al}_{2} \mathrm{O}_{3}=72 \%, \mathrm{SiO}_{2}=20 \%$, $\mathrm{Fe}_{2} \mathrm{O}_{3}=0.2 \%, \mathrm{CaO}-\mathrm{MgO}=0.3 \%, \mathrm{~K}_{2} \mathrm{O}-\mathrm{Na}_{2} \mathrm{O}=0.5 \%$, mean diameter $\left(\mathrm{D}_{50}\right)$ of $2 \mu \mathrm{m}$ (Synthetic Mullite M72, VAW, Veremigte, Werke AG, Germany).

\subsection{Thermogravimetric and microstructural SEM analysis}

The effect of heat treatment was also evaluated by thermogravimetric analysis and differential thermal analysis (DTA-TG) simultaneously carried out on a Netzsch $409 \mathrm{C}$ equipment with $5{ }^{\circ} \mathrm{C} / \mathrm{min}$. as heating rate in Pt crucibles in air atmosphere, posterior batch firing conditions for the clay were obtained after this analysis (table 2).

The evolution of the particle size and morphology of the clay and its fired products were examined by scanning electron microscopy SEM (Fei Quanta 200). Gold coated powders over carbon tape were analyzed in ultra-high vacuum conditions and $20.0 \mathrm{kV}$. An ETD detector was employed in back-scattered electron mode.

\section{3. $X R D$ procedure}

Identification and quantification of crystalline phases in the clays and fired materials were carried out by X-ray diffraction (XRD) (Philips 3020 with $\mathrm{Cu}-\mathrm{K} \alpha$ radiation, Ni filter, at $40 \mathrm{kV}-20 \mathrm{~mA}$ ); with $0.04^{\circ}$ and $2 \mathrm{~s}$ steps in the $3-70^{\circ}$ range.

The XRD patterns were analyzed with the program FullProf (version 4.90, July 2010) which is a multipurpose profile-fitting program (Rodríguez-Carvajal, 2001), including Rietveld refinement to perform phase quantification (Rietveld, 1969).

Le Bail demonstrated that it is possible to include the silica glass in the Rietveld refinement through a structural model with crystalline defects (Le Bail, 1995). Lutterotti et al. applied Le Bail method for the silica glass introducing defects from the crystal size for reproducing the peak widening (Lutterotti et al., 1998). This method strictly quantifies the glassy phase based in the actual XRD counts. In other words, the XRD intensity (band area) is proportional to the amount of glassy but diffracting silica phase. In the present work the amount of amorphous phase was estimated by this method. The employed quantification method was fully described in two previous works (Serra et al., 2013; Conconi et al., 2014).

\subsection{XANES procedure}

Al K-XANES spectra of aluminosilicate minerals were collected in Fluorescence mode on the Soft X-Rays Spectroscopy (SXS) beamline of the Brazilian Synchrotron Light Laboratory (LNLS, Campinas, Brazil). The beam focalization was performed using a Ni mirror. The monochromator employed was YB66, with a resolution of about $2 \mathrm{eV}$ for a slit aperture of $2 \mathrm{~mm}$. The incident photon energy was in the range of the Al Kedge for the experiments. The $I_{0}$ photon flux intensity was measured 
Table 1

Chemical composition of the studied clay.

\begin{tabular}{|c|c|c|c|c|c|c|c|c|}
\hline Oxide & $\mathrm{SiO}_{2}$ & $\mathrm{Al}_{2} \mathrm{O}_{3}$ & $\mathrm{Fe}_{2} \mathrm{O}_{3}$ & $\mathrm{MgO}$ & $\mathrm{K}_{2} \mathrm{O}$ & $\mathrm{TiO}_{2}$ & $\mathrm{CaO}$ & LOI \\
\hline$\%$ (wt.) & 54.4 & 32.9 & 0.70 & 0.60 & 0.49 & 0.25 & 0.11 & 10.3 \\
\hline
\end{tabular}

using a mesh of Au located before the main chamber. The photon energies were calibrated in Fluorescence mode using an Al metallic foil and setting the first inflection point to the energy of the K absorption edge of $\mathrm{Al}^{0}(1559 \mathrm{eV})$. The spectra were acquired at room temperature and the pressure chamber was about $10^{-4}$ Torr. The aluminosilicate minerals were ground into fine powder (standard mesh \# 200), and the powder samples were pressed uniformly on electric carbon tape supported on a stainless steel sample holder for XANES measurements. All spectra were normalized by $I_{f} / I_{0}$, where $I_{f}$ is the detected fluorescence intensity.

The pre-edge and the normalization background were realized by XANES Dactyloscope program (Klementev, 2001). The pre-edge background was subtracted using a polynomial function $a E^{-3}+b$, where $E$ is the energy in $\mathrm{eV}$, and $a$ and $b$ are two arbitrary parameters. The normalization was realized via average post-edge using a polynomial function.

\section{Results and discussion}

\subsection{Thermal behavior (TG-DTG) and thermal treatments}

Fig. 1 shows the TG and DTG analysis of the clay, the typical two mass losses can be observed in the $0-1400{ }^{\circ} \mathrm{C}$ range, the first one $\left(\approx 2 \%\right.$ ), observed below $150{ }^{\circ} \mathrm{C}$, corresponds to the surface water loss. The second one $(\approx 7 \%)$ mass loss can be observed at the kaolinite decomposition (dehydroxylation) into MK (also a water loss). This analysis permits to identify the transformation temperature. No other mass loss (or gain) process occurs in this temperature range. Fig. 2 shows the DTA curve, and both endothermic and exothermic processes can be detected.

The surface water loss presents an endothermic process, centered at $150^{\circ} \mathrm{C}$. A broad endothermic band centered at $538^{\circ} \mathrm{C}$, due to clay dehydroxylation reaction that is overlapped with $\alpha-\beta$ quartz transformation with less energy involved, is the most important peak of the DTA analysis. The observed temperatures correspond to the TG ones and the previously reported ones (Chakraborty, 2014). An exothermic peak is observed centered at $986{ }^{\circ} \mathrm{C}$; this corresponds to the metakaolinite transformation into a spinel type aluminosilicate (Eq. (2)). At higher temperatures a small and wide exothermic peak was measured in the

Table 2

Firing conditions and principal aluminum containing phases.

\begin{tabular}{llll}
\hline & $\begin{array}{l}\text { Transformation } \\
\text { temperature }\left({ }^{\circ} \mathrm{C}\right) \\
(\mathrm{DTA}-\mathrm{TG})\end{array}$ & $\begin{array}{l}\text { Firing } \\
\text { temperature } \\
\left({ }^{\circ} \mathrm{C}\right)\end{array}$ & $\begin{array}{l}\text { Principal aluminum } \\
\text { containing phase }\end{array}$ \\
\hline $\begin{array}{l}\text { Material } \\
\text { Kao-A }\end{array}$ & & 0 & Kaolinite (K) \\
Kao-B & & 500 & $\begin{array}{l}\text { Kaolinite }(\mathrm{K}) \\
\text { Metakaolinite (MK) } \\
\text { Kao-C }\end{array}$ \\
Kao-D & 565 & 800 & $\begin{array}{l}\text { Spinel type aluminosilicate } \\
\text { (SAS) }\end{array}$ \\
Kao-E & 1223 & 1100 & Mullite (M) \\
$\begin{array}{c}\text { Standard } \\
\text { Fischer } \\
\text { kaolin }\end{array}$ & & 1250 & Kaolinite (K) \\
$\begin{array}{c}\text { Sintered } \\
\text { mullite }\end{array}$ & & & Mullite (M) \\
\hline
\end{tabular}

$1200-1300{ }^{\circ} \mathrm{C}$ range, this corresponds to the mullite formation. Again, the detected temperatures correspond to the ones observed for similar materials (MacKenzie et al., 1985; Okada et al., 1986; Sanz et al., 1988). In fact, this wide peak consists in a couple of overlapped peaks centered at $1230{ }^{\circ} \mathrm{C}$ and $1250{ }^{\circ} \mathrm{C}$ that may correspond to both mullitization pathways (solid state transformations and crystallization) described in Eqs. (1) to (4) (Schneider et al., 2008; De Aza et al., 2014). In this preliminary study, these two phases were not differentiated.

Eqs. (1-4) illustrate these successive processes detected by TG-DTA. The simultaneous thermal analysis permitted to determine the actual temperature transformations, shown in Table 2. Based on TG-DTA information four materials were obtained after four thermal treatments that illustrate, together with the dried sample, the five steps of this process. Table 2 shows the conditions of these four materials fired in an electric kiln with $5{ }^{\circ} \mathrm{C} / \mathrm{min}$ of heating rate and $15 \mathrm{~min}$ of dwelling.

\subsection{XRD characterization}

Fig. 3 shows the XRD patterns of the crystalline standards: pure kaolin and sintered mullite, (F) and (M72) respectively. The XRDRietveld identification and quantification results are shown in Table 3. $\mathrm{F}$ consists in pure acid washed kaolin, and the principal phase is kaolinite, this is accompanied by some small amount titanium oxide (with a mass fraction less than 2\%). Besides the only crystalline phase in M72 is mullite, this is accompanied by $9 \%$ of amorphous phase. The amount of aluminum atoms in this amorphous phase would be low; hence the only important contribution to the XANES spectroscopy would be from the mullite phase.

Fig. 4 shows the XRD patterns of the studied materials. The principal diffraction peaks have been labeled; the patterns have a vertical offset for clarity. Table 3 summarizes the evaluated phases in each material and standards. The crystalline degree is also pointed out for each phase.

The identified phases are: the starting commercial kaolin (Kao-A) consisting in kaolinite unpurified by quartz and feldspars, the actual proportion were evaluated by Rietveld refinement (Table 3). No important changes were observed after thermal treatment at $500{ }^{\circ} \mathrm{C}$ (Kao-B). The only XRD manifestations observed in the material treated at $800{ }^{\circ} \mathrm{C}$ (Kao-C) are Quartz and Feldspar, evidencing the absence of visible XRD pattern of the product after thermal decomposition (dehydroxylation)

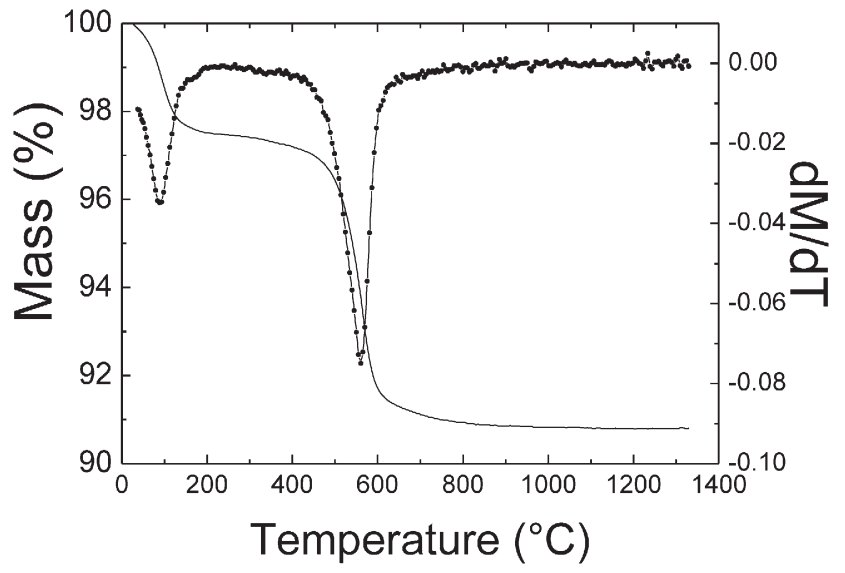

Fig. 1. Thermogravimetric analysis of the kaolinitic clay. Solid line corresponds to TG, and scattered line corresponds to DTG. 


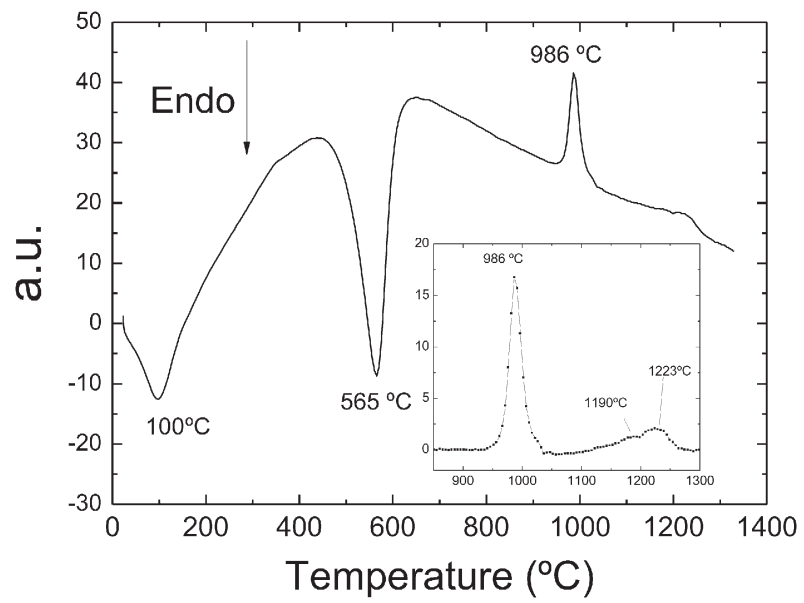

Fig. 2. Differential thermal analysis of the kaolinitic clay. Peaks were identified with the local minimum or maximums.

of the kaolinite. This type of material, metakaolin (Blinder and Nakahira, 1959a), presents low degree of crystallinity (MacKenzie et al., 1985; Lee et al., 2003; White et al., 2011). As it was mentioned, the structure of metakaolin has been studied by different experimental and theoretical techniques (Mitra and Bhattacherjee, 1970; MacKenzie et al., 1985; Lee et al., 2003; White et al., 2011; Chakraborty, 2014), and some controversies are still open (White et al., 2011; Chakraborty, 2014). The local characterization performed in this work by Al K-XANES is destined to elucidate the presence of amorphous or low order structures during temperature transformations.

The Le Bail glass quantification was employed to refine silica glass amorphous structures by the XRD pattern of the Kao-D material (treated at $1100{ }^{\circ} \mathrm{C}$ ). On the other hand, this approach was not employed for MK because this phase do not presents a vitreous structure (Le Bail, 1995; Chakraborty, 2014). The glass product of the MK (strictly amorphous) is transformed into SAS and the feldspar fusion can be pondered by this method; in fact, the amount of glassy phase slightly overcomes the $50 \%$ for Kao-D material. The spinel type aluminosilicate (SAS) previously described by other techniques (Brown et al., 1985; Okada et al., 1986; Sainz et al., 2000) is also difficult to characterize by standard XRD analysis, and cannot be assumed as amorphous to be pondered by the Le Bail method. The actual proportions of SAS are also shown in Table 3.

Finally, Kao-E presents mullite and quarts as principal phases, being cristobalite also detected. The amount of glass is lower than in Kao-D because of the crystallization of mullite. No low crystalline phases are expected because both MK and SAS phases should have react after the thermal treatment $\left(1250{ }^{\circ} \mathrm{C}\right)$. Considering the degree of crystallization, the adequatechoose of X-ray technique for each phase is shown in Table 3.

\subsection{SEM characterization of the kaolinite and the calcined clay}

Fig. 5 (A, B, C and D) shows the SEM images of the studied clays and the fired clays. In the first one $(A)$ the typical laminar structure can be observed, this corresponds with the images reported in literature (Frost et al., 2002), the sub-micronic size can be easily observed, particularly the lamina heights are around $100 \mathrm{~nm}$ and are piled up.

In Fig. 5B the Kao-C material image is shown, the stack distribution was modified by heat the treatment $\left(800{ }^{\circ} \mathrm{C}\right)$, besides the size and shape of laminas remained unchanged, this fact was previously reported as well (Ortega et al., 2010).

A disordered layers distribution can be observed in the SEM image (Fig. 5C) corresponding to the Kao-D material. This shows the material

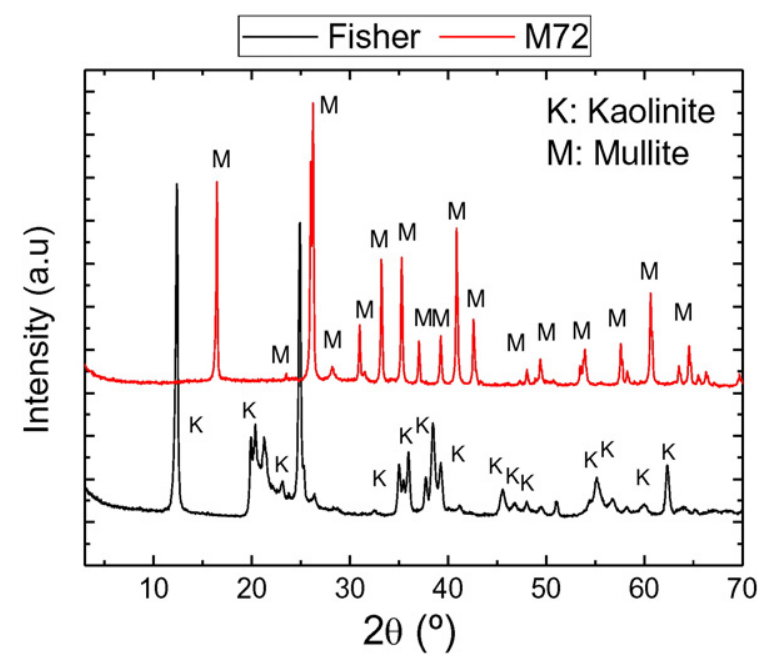

Fig. 3. XRD patterns of the employed materials as structural standards: acid washed kaolin (F) and sintered mullite (M72).

after the thermal treatment at $1100{ }^{\circ} \mathrm{C}$, its microstructure is similar to the one observed after $800{ }^{\circ} \mathrm{C}$. The only difference is the appearance of more rounded edges and rounded sub-micrometric particles. This might correspond to the produced amorphous glass $\left(\mathrm{SiO}_{2}\right)$ from the metakaolin transformation at $980^{\circ} \mathrm{C}$ and from the partial (superficial) fusion of the quartz-feldspars impurities. It is important to point out that the disordered laminar structure can be easily observed and contrasts to the stacked observed distribution in Kao-A in image A.

Finally, Fig. 5D shows the powder fired at higher temperatures. After treatments at $1250^{\circ} \mathrm{C}$ the mullitization is complete or almost complete (Schneider et al., 2008). The sintered powder was milled before the SEM characterization. No clay or clay-like (laminar) particles can be observed in the images nor detected by XRD. Fragile fractured sintered particles were observed, which corresponds to the high amorphous phase detected by XRD. Mullite particles are imbibed in this glassy phase. Important amount of sub-micrometric agglomerated particles were obtained after milling treatment.

The performed characterizations give enough contexts for the $\mathrm{Al} \mathrm{K}$ XANES analysis shown in the following section, the described thermal processes present local and long distance order nature, XRD analysis complemented with thermal analysis and microscopy permitted to ensure advance of the thermal processes.

\subsection{Al K-XANES characterization of the kaolinite and the calcined clay}

Fig. 6A shows the Al K-edge XANES spectra, obtained in fluorescence mode, for crystalline standards: pure kaolin $\mathrm{K}(\mathrm{F})$ and sintered mullite (M72). Kaolinite has a low symmetry with octahedrons linked by the edge to form a layer where only $2 / 3$ of octahedral sites are occupied by $\mathrm{Al}$ (Ildefonse et al., 1998), and two Al sites in very distorted octahedron with Al-O distances between 1.880 and $1.969 \AA$ (Bish and Von Dreele, 1989). The six distinguishable features marked in the $\mathrm{Al} \mathrm{K-}$ XANES spectra for Kaolinite reference compound are interpretable as indicated by Li et al. (Li et al., 1995). In our case, the first feature (labeled as 1 ) at $1565.8 \mathrm{eV}$ is probably related to a pre-edge feature associated to $1 \mathrm{~s} \rightarrow \mathrm{a}_{1 \mathrm{~g}}$ ( $3 \mathrm{~s}$-like) electronic transition. The second feature (labeled as 2 ) is located at $1568.0 \mathrm{eV}$ and is associated with a $1 \mathrm{~s} \rightarrow \mathrm{t}_{1 \mathrm{u}}$ (3p-like) transition. Peak 3 is at $1570.4 \mathrm{eV}$ and can be identified with a multiple scattering resonance. Shoulder 4, at $1573.2 \mathrm{eV}$, is associated with $1 \mathrm{~s} \rightarrow \mathrm{t}_{2 \mathrm{~g}}$ (3d-like) transition. At higher energies, 5 and 6 resonances occur at 1579.0 and $1589.5 \mathrm{eV}$, and they are identified with multiple scattering resonances and $1 \mathrm{~s} \rightarrow \mathrm{e}_{\mathrm{g}}$ (3d-like) transitions respectively (Li et al., 1995). All peak positions in present XANES spectra are in 
Table 3

Phase quantification for each of the materials studied, and employed standards, crystalline grade and the corresponding suitable X-ray analysis.

\begin{tabular}{|c|c|c|c|c|c|c|c|c|c|c|}
\hline \multirow[t]{2}{*}{ Phase } & \multirow[t]{2}{*}{ Crystalline grade } & \multicolumn{5}{|c|}{ Material } & \multicolumn{2}{|c|}{ Standards } & \multicolumn{2}{|c|}{$\mathrm{X}$-ray based technique } \\
\hline & & Kao-A & Kao-B & Kao-C & Kao-D & Kao-E & Fischer & Mullite & XRD & Spectroscopy (Al K edge) XANES \\
\hline Kaolinite & High & 71.7 & 64.5 & & & & 98.0 & & Yes & Yes \\
\hline Quartz & High & 21.2 & 26.5 & 76.9 & 43.3 & 23.4 & Traces & Traces & Yes & No \\
\hline Cristobalite & High & & & & & 1.9 & Traces & Traces & Yes & No \\
\hline Feldspar (ortoclase) & High & 7.1 & 9.0 & 23.1 & 0.3 & & & & Yes & Yes \\
\hline $\mathrm{TiO}_{2}$ (anatase) & & & & & & & 2.0 & & & \\
\hline Metakaolin & Low & & & Unknown & & & & & No & Yes \\
\hline Spinel type aliminosilicate SAS & Low & & & & Unknown & & & & No & Yes \\
\hline Mullite & High & & & & 2.8 & 42.4 & & 92 & Yes & Yes \\
\hline Glass phase & Null & & & & 51.2 & 23.4 & & 8 & (Indirect) & Yes \\
\hline
\end{tabular}

agreement with the reported ones in the literature (Li et al., 1995; Gehlen et al., 2002).

In the case of Mullite, the peak assignment presents more difficulties due to large number of phases belonging to the family of mullite-type structures (Bellotto et al., 1995b; Schneider et al., 2008; Chakraborty, 2014). The crystal structure of mullite is characterized by $\mathrm{AlO}_{6}$ octahedral chains parallel to crystallographic c-axis, and $(\mathrm{Al}-\mathrm{Si}) \mathrm{O}_{4}$ tetrahedral chains parallel to $a$ and $b$-axes (Schneider et al., 2008).

Fig. 6B shows the Al K-XANES spectra for the samples with different thermal treatment (see Table 2). The Al K-XANES spectra showed in curve 6 A for Kao-A (dot line) and Kao-B (solid line), shows the similarity between both spectra and whit the XANES spectra of Kaolinite analytical compound $\mathrm{K}(\mathrm{F})$. The small difference in intensity at peak 3 can be attributed to the disorder at the Al-neighboring (Bugaev et al., 1998).

MK Al K-XANES spectra (White et al., 2011), with the four main features indicated as $1^{\prime}, 2^{\prime}, 3^{\prime}$ and $4^{\prime}$, is show in (Kao-C). In our case, there is a small shoulder at $1563 \mathrm{eV}\left(1^{\prime}\right)$, the main peak (2') at $1567 \mathrm{eV}$, peak $3^{\prime}$ is at $1571.5 \mathrm{eV}$ and the fourth one is at $1585 \mathrm{eV}$. The origin of shoulder $1^{\prime}$ is due to the presence of a mixed nonbonding s, p, d orbitals, which are empty due to the unsaturated nature of the III-Al coordination (van Bokhoven et al., 2003). Peaks $2^{\prime}$ and $4^{\prime}$ are assigned as distinctive from MK (White et al., 2011), where $2^{\prime}$ is associated to IV-Al, and $4^{\prime}$ is associated to multiple scattering effects in the first Al-O coordination shell and can be interpreted as the concentration of $\mathrm{V}$-Al (Neuville et al., 2008; White et al., 2011). For example, Sanz et al. assigned the 30 ppm intensity peak in ${ }^{27} \mathrm{Al}$ MAS-NMR to penta-coordinated atoms. The authors propose a structure with two Al atoms sharing two oxygens, corresponding to two $\mathrm{OH}-\mathrm{Groups}$. Each $\mathrm{Al}$ is coordinated to three other tetrahedral oxygens (Sanz et al., 1988). The 3'-peak has a controversial assignment: some authors suggest that represents a

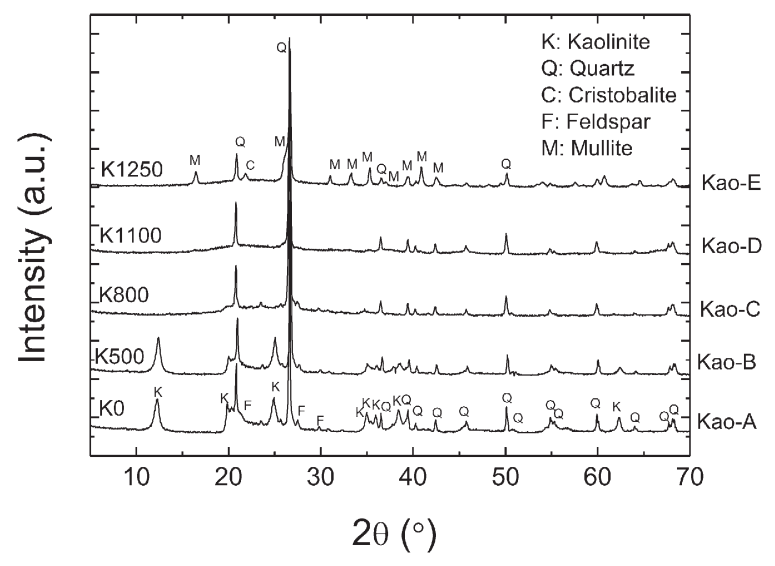

Fig. 4. XRD patterns of the obtained materials after different thermal treatments. reasonably high concentration of $\mathrm{VI}-\mathrm{Al}$-peak in metakaolin, which is similar in energy position at 3-peak in K (Gehlen et al., 2002); others authors showed that this peak can be assigned to $\mathrm{V}$-Al (Neuville et al., 2008). Several investigations strongly point towards this peak is due to $\mathrm{V}$-fold aluminum, although it cannot fully exclude the presence of VI-Al (White et al., 2011). It is not our purpose to elucidate in detail the $\mathrm{Al}$-nature in $\mathrm{MK}$ with present experiments; however, we may note their consistency with previous results in the Al coordination changes occurred in the kaolinite dehydroxylation process. The thermal delamination of the laminar structure, together with the border effect might also explain de presence of the odd Al coordinations (III and V).

At about $980^{\circ} \mathrm{C}$ (see DTA in Fig. 2) there is a phase change MK $\rightarrow$ SAS. In Fig. 6B (Kao-D) shows the Al K-XANES spectra for of a material with SAS as principal Al containing phase. The problem regarding the composition of spinel phase still remains, and it is the proper characterization of spinel phase whether it is simple $\gamma-\mathrm{Al}_{2} \mathrm{O}_{3}$ or $\mathrm{Al}-\mathrm{Si}$ spinel (Chakraborty, 2014). Considering XANES technique as "fingerprint technique" and using reference spectra published in the literature (Yoon et al., 2004; Tatsumi et al., 2008; Li et al., 2015) it can be seen that there are characteristics of the Al K-XANES gamma-alumina spectra present in the Kao-D spectra. This evidence favors the interpretation of the formation of $\gamma-\mathrm{Al}_{2} \mathrm{O}_{3}$ spinel at the first exothermic peak $\left(\sim 980^{\circ} \mathrm{C}\right)$. To make an unambiguous determination $\mathrm{Al}$ K-XANES experiments are needed, with pure $\gamma-\mathrm{Al}_{2} \mathrm{O}_{3}$ spinel as reference and $\mathrm{Al} \mathrm{K}$-XANES simulations.

Fig. 6B (Kao-E) shows the Al K-XANES spectrum of the material with $\mathrm{Mi}$ and Mii as principal aluminum containing phases. The SAS transformation into Mi (Eq. (3)) and Mii crystallization (Eq. (4)) occurred below $1250^{\circ} \mathrm{C}$.

In general, XANES spectra of aluminum-containing oxides showed three distinguishable peaks: one at $1566.0 \mathrm{eV}$, assignable to tetrahedral $\mathrm{AlO}_{4}$, and two at $1568.0 \mathrm{eV}$ and $1572.0 \mathrm{eV}$ characteristic of octahedral $\mathrm{AlO}_{6}$ (Kato et al., 2001). In the case of SAS, there are several features, particularly there is a shoulder at $1566 \mathrm{eV}$ and two peaks at $1567.8 \mathrm{eV}$ and $1571.4 \mathrm{eV}$. For $\mathrm{Mi}(+\mathrm{G})$, heat treatment at $1250^{\circ} \mathrm{C}$, the peak definition is more complicated due a left-shift of the second peak. The first peak is at $1566.3 \mathrm{eV}$, the second at $1567.3 \mathrm{eV}$ and the third one at $1571.3 \mathrm{eV}$. In agreement with the interpretation given by Kato et al., there are evidences to suggest the existence of IV-Al and VI-Al (Kato et al., 2001).

In Table 4 the principal Al-coordination characteristics obtained by Al K-XANES for the sites of the aluminum in these systems are summarized. This characterization is complementary to that performed by XRD.

No important changes were observed after the $500{ }^{\circ} \mathrm{C}$ thermal treatment in Kao-B by XRD and Al K-XANES. By XRD it was observed that MK presents a low degree of crystallinity, while XANES indicates the presence of characteristics corresponding to four different sites for aluminum. The spinel type aluminosilicate (SAS; Kao-D) is also difficult to characterize by standard XRD analysis, but XANES characterization 

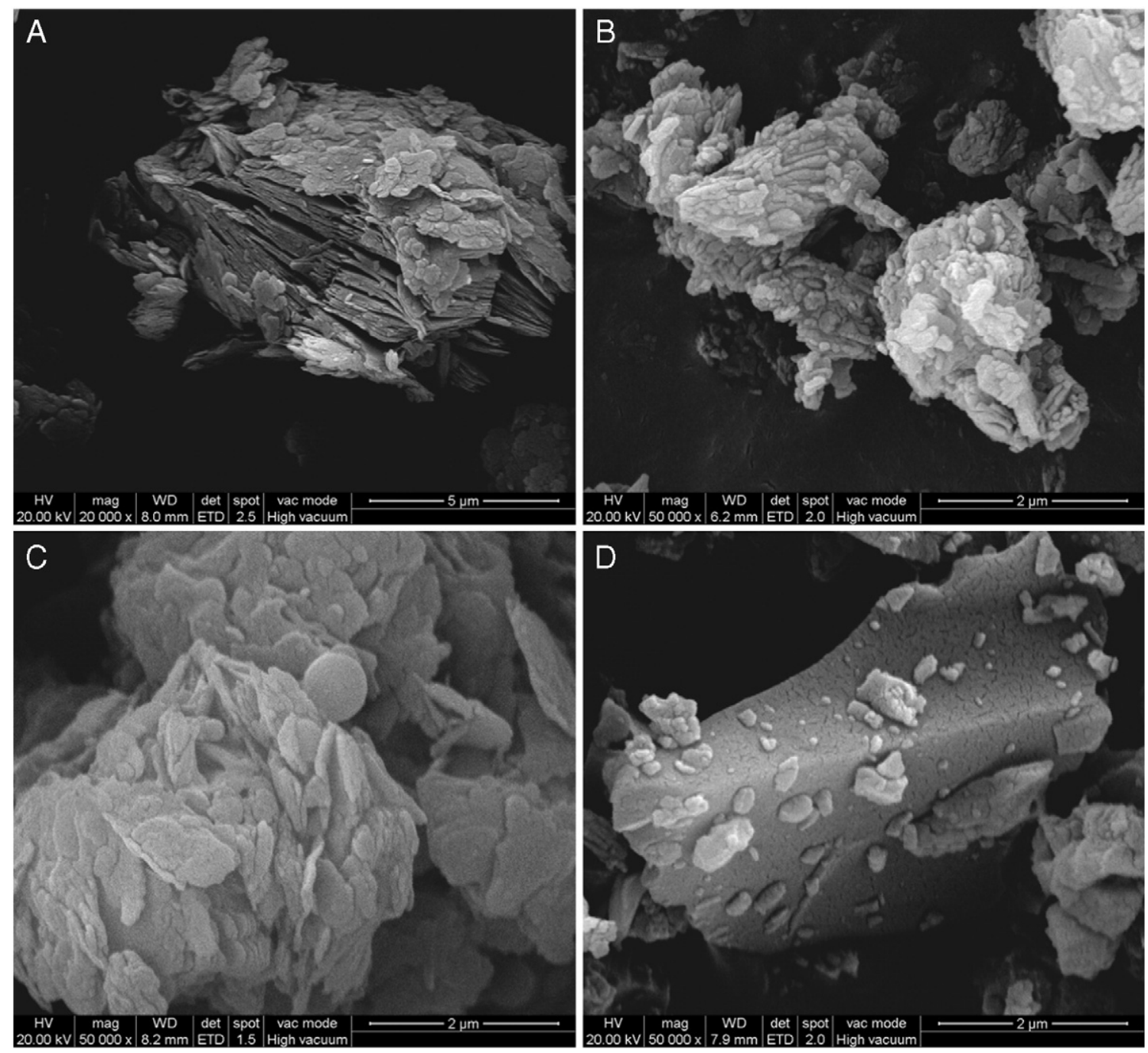

Fig. 5. SEM images (A,B,C and D) of the clay and the fired clays (Kao-A, Kao-C, Kao-D and Kao-E, respectively).

allows the determination and characterization of the two principal characteristic sites for the local Al environment (IV and VI). Kao-E presents mullite and quartz as principal phases detected by XRD and also observed by Al K-XANES.

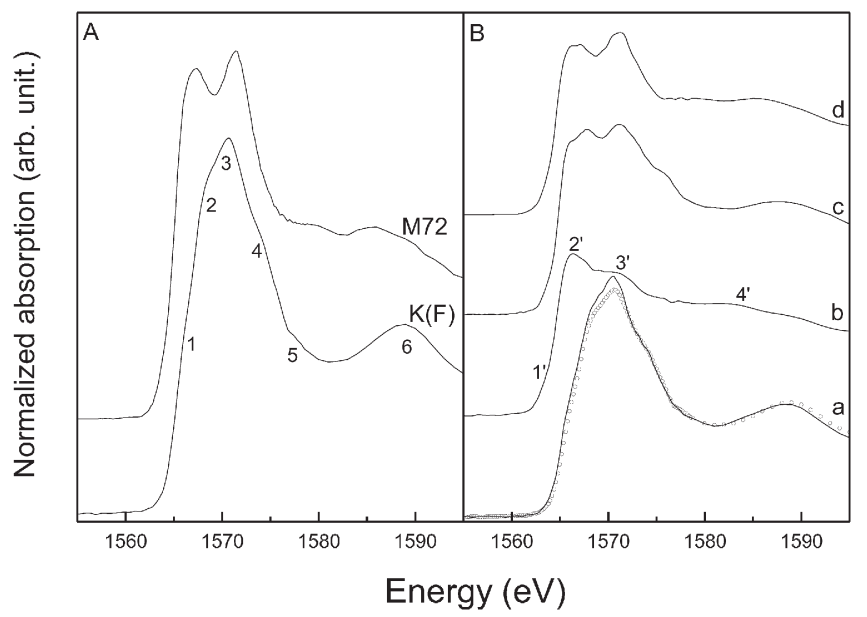

Fig. 6. Al K-edge XANES spectra of (A) references compounds analytical Kaolinite $K(F)$, and Mullite M72. (B) sample Kao-A (dotted line) and its fired products (Kao-B, Kao-C, Kao-D and Kao-E, curves a, b, c and d, respectively) corresponding to K-MK-SAS-M series.

\section{Conclusions}

Kaolinite thermal processes present local and long distance order nature. The extended and local range order structure characterization of kaolinitic clay and its calcination products was carried out by means of two X-ray based techniques: XRD and XANES, respectively. In order to give context to these characterizations thermal analysis (TG-DTA) and electron scanning microscopy were carried out.

Table 4

Aluminum coordination for each of the studied material and the employed reference compounds.

\begin{tabular}{|c|c|c|c|c|}
\hline & \multicolumn{4}{|c|}{ Coordination of Al obtained by XANES } \\
\hline & III & IV & $\mathrm{V}$ & $\mathrm{VI}$ \\
\hline \multicolumn{5}{|l|}{ Material } \\
\hline \multicolumn{5}{|l|}{ Kao-A } \\
\hline Kao-B & \multirow{4}{*}{ Yes } & & \multirow{4}{*}{ Yes } & Yes \\
\hline Kao-C & & Yes & & Yes \\
\hline Kao-D & & Yes & & Yes \\
\hline Kao-E & & Yes & & Yes \\
\hline \multicolumn{5}{|l|}{ Standard } \\
\hline Fischer kaolin & & & & Yes \\
\hline Sintered mullite & & Yes & & Yes \\
\hline
\end{tabular}


Both crystalline and low crystalline phases were described after thermal transformations in kaolinitic clays: Kaolinite, metakaolinite, the spinel type aluminosilicate and mullite. The XRD analysis permitted to quantify the amount of strictly amorphous (non-crystalline) phases produced during the thermal reactions of the starting powders, consistently with TG-DTA and SEM analysis. Microstructure changes were described by SEM analysis. This presented a clear behavior and allows us to identify the proper thermal treatments in order to achieve the complete transformation of the material.

Aluminum atoms in the different materials were locally described and compared by Al K-XANES. Both coordination geometries and first neighbors were established in each phase and consistently compared with further studies on aluminum oxides and minerals. Al has octahedral coordination in kaolinite, and III-Al, V-Al and VI-Al coordination were identified for metakaolin. Finally, IV-Al and VI-Al were found in the spinel type aluminosilicate and mullite.

The results confirm the potentiality of the synchrotron based techniques for the characterization of natural materials especially with low crystallinity. These might complement the XRD traditional characterization. This spectroscopy might present enough resolution for more slight local structure changes like chemical substitutions, doping or structure changes resulting from mechanochemical treatments.

\section{References}

Bellotto, M., Gualtieri, A., Artioli, G., Clark, S.-M., 1995a. Kinetic study of the kaolinitemullite reaction sequence. Part I: kaolinite dehydroxylation. Phys. Chem. Miner. 22 207-214.

Bellotto, M., Gualtieri, A., Artioli, G., Clark, S.-M., 1995b. Kinetic study of the kaolinitemullite reaction sequence. Part II: mullite formation. Phys. Chem. Miner. 22, 215-222.

Bish, D.L., Von Dreele, R.B., 1989. Rietveld refinement of non-hydrogen atomic positions in kaolinite. Clay Clay Miner. 37, 289-296.

Blinder, W.B., Nakahira, M., 1959a. The kaolinite-mullite reaction series (I, II, III). J. Am. Ceram. Soc. 42, 311-324.

Blinder, W.B., Nakahira, M., 1959b. The kaolinite-mullite reaction series (IV). J. Am. Ceram. Soc. 44, 506-507.

Brown, I.W.M., MacKenzie, K.J.D., Bowden, M.E., Meinhold, R.H., 1985. Outstanding problems in the kaolinite-mullite reaction sequence investigated by ${ }^{29} \mathrm{Si}$ and ${ }^{27} \mathrm{Al}$ solidstate nuclear magnetic resonance: II, high-temperature transformations of metakaolinite. J. Am. Ceram. Soc. 68, 298-301.

Bugaev, L.A., Ildefonse, P., Flank, A.M., Sokolenko, A.P., Dmitrienko, H.V., 1998. Aluminum $\mathrm{K}$-XANES spectra in minerals as a source of information on their local atomic structure. J. Phys. Condens. Matter 10, 5463-5473.

Bunker, G., 2010. Introduction to XAFS. A Practical Guide to X-ray Absorption Fine Structure Spectroscopy. Cambridge University Press, Cambridge.

Carbajal, L., Rubio-Marcos, F., Bengochea, M.A., Fernandez, J.F., 2007. Properties related phase evolution in porcelain ceramics. J. Eur. Ceram. Soc. 27, 4065-4069.

Carty, W.M., Senapati, U., 1998. Porcelain-raw materials, processing, phase evolution and mechanical behaviour. J. Am. Ceram. Soc. 81, 3-20.

Chakraborty, A.K., 2014. Phase Transformation of Kaolinite Clay. Springer, New Delhi.

Conconi, M.S., Gauna, M.R., Serra, M.F., Suarez, G., Aglietti, E.F., Rendtorff, N.M., 2014 Quantitative firing transformations of a triaxial ceramic by X-ray diffraction methods. Cerâmica 60, 524-531.

De Aza, A.H., Turrillas, X., Rodriguez, M.A., Duran, T., Pena, P., 2014. Time-resolved powder neutron diffraction study of the phase transformation sequence of kaolinite to mullite. J. Eur. Ceram. Soc. 34, 1409-1421.

Frost, R.L., Van Der Gaast, S.J., Zbik, M., Kloprogge, J.T., Paroz, G.N., 2002. Birdwood kaolinite: a highly ordered kaolinite that is difficult to intercalate. An XRD, SEM and Raman spectroscopic study. Appl. Clay Sci. 20, 177-187.

Gehlen, M., Beck, L., Calas, G., Flank, A.M., Van Bennekom, A.J., Van Beusekom, J.E.E., 2002 Unraveling the atomic structure of biogenic silica: evidence of the structural association of Al and $\mathrm{Si}$ in diatom frustules. Geochim. Cosmochim. Acta 66, 1601-1609.

Ildefonse, P., Cabaret, D., Sainctavit, P., Calas, G., Flank, A.M., Lagarde, P., 1998. Aluminium $\mathrm{X}$-ray absorption near edge structure in model compounds and Earth's surface minerals. Phys. Chem. Miner. 25, 112-121.

Iqbal, Y., Lee, W.E., 2000. Microstructural evolution in triaxial porcelain. J. Am. Ceram. Soc. $83,3121-3127$
Kato, Y., Shimizu, K.I., Matsushita, N., Yoshida, T., Yoshida, H., Satsuma, A., Hattori, T., 2001. Quantification of aluminium coordinations in alumina and silica-alumina by $\mathrm{Al} \mathrm{K-}$ edge XANES. Phys. Chem. Chem. Phys. 3, 1925-1929.

Klementev, K.V., 2001. Deconvolution problems in X-ray absorption fine structure spectroscopy. J. Phys. D. Appl. Phys. 34, 2241-2247.

Koningsberger, D.C., Prins, R., 1998. X-ray Absorption: Principles, Applications, Techniques of EXAFS, SEXAFS, and XANES. John Wiley and Sons. York, New.

Le Bail, A., 1995. Modelling the silica glass structure by the Rietveld method. J. Non-Cryst. Solids 183, 39-42.

Lee, S., Kim, Y.J., Moon, H.S., 2003. Energy-filtering transmission electron microscopy (EFTEM) study of a modulated structure in metakaolinite, represented by a $14 \AA$ modulation. J. Am. Ceram. Soc. 86, 174-176.

Lee, W.E., Sarvornpanich, T., Iqbal, Y., 2008. Mullite formation in clays and clay-derived vitreous ceramics. J. Eur. Ceram. Soc. 28, 465-471.

Li, B., Leng, K., Zhang, Y., Dynes, J.J., Wang, J., Hu, Y., Ma, D., Shi, Z., Zhu, L., Sun, Y., Chrzanowski, M., Ma, S., 2015. Metal-organic framework based upon the synergy of a Brønsted acid framework and Lewis acid centers as a highly efficient heterogeneous catalyst for fixed-bed reactions. J. Am. Chem. Soc. 137, 4243-4248.

Li, D., Bancroft, G.M., Fleet, M.E., Feng, X.H., Pan, Y., 1995. Al K-edge XANES spectra of aluminosilicate minerals. Am. Mineral. 80, 432-440.

Lisiane, N.L.S., Bartolomeu, J.S., Wherllyson, P.G., Juliana, M.C., Bruna, S.L., Renato, C.S., Romualdo, R.M., 2012. Influence of firing conditions on properties of red ceramic. Mater. Sci. Forum 727-728, 721-726.

Liu, X.J., Sun, X.W., Zhang, J.J., Pu, X.P., Ge, Q.M., Huang, L.P., 2003. Fabrication of $\beta$-sialon powder from kaolin. Mater. Res. Bull. 38, 1939-1948.

Lutterotti, L., Ceccato, R., Dal Maschio, R., Pagani, E., 1998. Quantitative analysis of silicate glass in ceramic materials by the Rietveld method. Mater. Sci. Forum 278, 87-92.

MacKenzie, K.J.D., Brown, I.W.M., Meinhold, R.H., Bowden, M.E., 1985. Outstanding problems in the kaolinite-mullite reaction sequence investigated by ${ }^{29} \mathrm{Si}$ and ${ }^{27} \mathrm{Al}$ solidstate nuclear magnetic resonance: I, metakaolinite. J. Am. Ceram. Soc. 68, 293-297.

Mitra, G.T., Bhattacherjee, S., 1970. X-ray diffraction studies on the transformation of kaolinite into metakaolin. II. Study of layer shift. Acta Crystallogr. Sect. B: Struct. Sci. 26, 2124-2128

Neuville, D.R., Cormier, L., De Ligny, D., Roux, J., Flank, A.M., Lagarde, P., 2008. Environments around $\mathrm{Al}, \mathrm{Si}$, and $\mathrm{Ca}$ in aluminate and aluminosilicate melts by X-ray absorption spectroscopy at high temperature. Am. Mineral. 93, 228-234.

Okada, K., Otsuka, N., Ossaka, J., 1986. Characterization of spinel phase formed in the kaolin-mullite thermal sequence. J. Am. Ceram. Soc. 69, C251-C253.

Ortega, A., Macías, M., Gotor, F.J., 2010. The multistep nature of the kaolinite dehydroxylation: kinetics and mechanism. J. Am. Ceram. Soc. 93, 197-203.

Rietveld, H., 1969. A profile refinement method for nuclear and magnetic structures. J. Appl. Crystallogr. 2, 65-71.

Rodríguez-Carvajal, J., 2001. Recent developments of the program FULLPROF, in commission on powder diffraction (IUCr). Newsletter 26, 12-19.

Sainz, M.A., Serrano, F.J., Amigo, J.M., Bastida, J., Caballero, A., 2000. XRD microstructural analysis of mullites obtained from kaolinite-alumina mixtures. J. Eur. Ceram. Soc. $20,403-412$.

Sanz, J., Madani, A., Serratosa, J.M., Moya, J.S., Aza, S., 1988. ${ }^{27-}$ Aluminum and ${ }^{29-}$ siliconmagic-angle spinning nuclear magnetic resonance study of the kaolinite-mullite transformation. J. Am. Ceram. Soc. 7, C418-C421.

Schneider, H., Schreuer, J., Hildmann, B., 2008. Structure and properties of mullite. A review. J. Eur. Ceram. Soc. 28, 329-344.

Serra, M.F., Conconi, M.S., Suarez, G., Agietti, E.F., Rendtorff, N.M., 2013. Firing transformations of an Argentinean calcareous commercial clay. Cerâmica 59, 254-261.

She, J.H., Ohji, T., 2003. Fabrication and characterization of higly porous mullite ceramics. Mater. Chem. Phys. 80, 610-614.

Tatsumi, K., Sasano, Y., Muto, S. Yoshida, T., Sasaki, T., Horibuchi, K., Takeuchi, Y., Ukyo, Y 2008. Local atomic and electronic structures around $\mathrm{Mg}$ and $\mathrm{Al}$ dopants in LiNiO 2 electrodes studied by XANES and ELNES and first-principles calculations. Phys. Rev. B 78, 045108-8

van Bokhoven, J.A., Van der Eerden, A.M., Koningsberger, D.C., 2003. Three-coordinate aluminum in zeolites observed with in situ X-ray absorption near-edge spectroscopy at the Al K-edge: flexibility of aluminum coordinations in zeolites. J. Am. Chem. Soc. 125, 7435-7442.

Wang, M.R., Guo, N., He, P.G., Yu, J.B., Jia, D.C., 2014. Formation mechanism and its pozzolanic activity of metakaolin. Key Eng. Mater. 602-603, 620-623.

White, C.E., Perander, L.M., Provis, J.L., van Deventer, J.S., 2011. The use of XANES to clarify issues related to bonding environments in metakaolin: a discussion of the paper $\mathrm{S}$. Sperinck et al., "Dehydroxylation of kaolinite to metakaolin-a molecular dynamics study". J. Mater. Chem. 21, 7007-7010.

Yoon, T.H., Johnson, S.B., Benzerara, K., Doyle, C.S., Tyliszczak, T., Shuh, D.K., Brown, G.E., 2004. In situ characterization of aluminum-containing mineral-microorganism aqueous suspensions using scanning transmission X-ray microscopy. Langmuir 20, 10361-10366. 